\title{
Blogging as a reflective journaling tool
}

\section{Moira Dunworth ${ }^{1}$ and Non Scantlebury ${ }^{2}$}

Summary: While web-based tools are increasingly being used in social work education, there remains some reluctance among social workers and social work educators to explore the use of the new web 2.0 tools. Set in the context of good practice development, this paper outlines how blogging was used to write reflective journals during a social work placement. The practical obstacles are described, along with solutions and advice about confidentiality. Issues relating to reflective writing are as relevant to blogging as to a paper-based medium and blogging may be a means by which practice teachers can improve their support of students, particularly when working at a distance. Students concluded that blogging their reflective journals saved time, enabled more immediacy in their contact with the practice teacher and helped them to develop more confidence and skill in using web-based technologies. The practice teacher benefited from this development in that it gave her more regular and convenient access to the students' work and reflections and allowed her to offer support between meetings, particularly in times of difficulty for the students. The success of this project suggests that there is scope for introducing other web 2.0 tools to support practice teaching with students.

Keywords: blogging, practice teaching, reflective journal, elearning, social work education, social work

1. Independent Practice Teacher

2. Learning Resources Development Manager, The Open University Library

Address for Correspondence: Moira Dunworth, 104/4 St Stephen Street, Edinburgh EH3 5AQ, UK moira.dunworth@btopenworld.com

6 Journal of Practice Teaching \& Learning 7(3) 2006-07, pp.6-21. DOI: 10.1921/19640. @ wE-b 
Blogging as a reflective journaling tool

\section{Introduction}

While social workers tend to see themselves as not fully engaged in the technological revolution, 'I'm no good at computers', being an oft-heard comment, the use of online databases to support knowledge management is now widespread in social work. The requirements for social work training in the UK now include competence in working with computers:

Make sure that the candidate has the potential and willingness to learn the basic information technology and communication (ICT) skills they need to get the European Computer Driving Licence, or its equivalent, by the end of their first year of study. (Scottish Government, 2003)

It is therefore timely to consider what aspects of elearning might be offered by practice teachers to support the development of competence and confidence in using technologies effectively. This paper outlines the use of one web 2.0 tool, blogging, as part of a placement managed by an off-site practice teacher. The expression 'web 2.0 tools' refers to a second generation of web-based communities and hosted services, such as social-networking sites and wikis. These aim to facilitate collaboration and sharing between users. I include blogging in my interpretation of 'web 2.0 tools', although blogging is no longer very new.

As a Practice Teacher I encouraged my students to engage with blogging as a reflective journaling tool. This paper sets out what I did and why and includes some detail about my journey in finding solutions to the challenges which arose. The success of the project is measured in terms of feedback from the students at the end of the placement and via interviews with those students five months later. The eventual enthusiastic engagement of two students who were initially unsure of their competence in any computer-related activity is also an indicator of the possibilities of using this tool more broadly to support the development of ICT competence in line with standards requirements.

Blogging was offered as a tool by which the students could present their reflective journal. Studies (Watson, 2007b; Davison Turley, 2005; Ojala, 2005; Dearstyne, 2005) reviewed for this article suggest that blogging can play a useful role in underpinning the broader knowledge and information management needs of users in different settings. Whilst highlighting the power of blogging to support convenient and effective ways of keeping users up to date and informed, several core

7 Journal of Practice Teaching \& Learning 7(3) 2006-07, pp.6-21. DOI: 10.1921/19640. @ w\&b 
information management issues surfaced. These were across different practice areas, particularly around issues relating to identity and security management and policy guidance needed around the use of blogging in specific contexts.

In order for the introduction of any learning technology to be successful, that technology must be appropriate to the learning context and its rationale must be clearly understood and accepted by the teachers and the students (Sharpe et al, 2006). While it is tempting to use new tools just because they are available, educators should take note of Tolmie and Boyle's (2000) conditions for success in online communication, conditions which include clarity, ownership, a shared understanding of the need for the tool and usability.

Studies undertaken on the communication preferences of social care practitioners revealed that social workers prefer to acquire their knowledge direct from colleagues and from practice rather than from research overviews available on the internet (Cha et al, 2006; Forrest and Williams, 1987). Watson (2007b) highlights recent initiatives aimed to encourage the sector to take up new forms of knowledge management and networking opportunities, for example, the Improvement and Development Agency discussion forums; the Knowledge Exchange; and the Care Services Improvement Partnership Knowledge Community. Watson goes on to state 'there appears to be an as yet untapped potential to enable practitioners, service users and others' (p.43) to engage in publication structures outside of those linked to more formal academic publishing which are both accessible and meaningful.

Watson places blogging within a range of technologies and processes which aim to build on the real potential of tacit knowledge and information management sharing in order to support good practice developments. However, given that social work, as a profession, may not have widely embraced the potential applications of web 2.0 tools in their work (Watson 2007a), social work students are not always challenged to engage with them.

\section{Blogging}

Conceived as a 'web-log', a blog is a web-based journal which is created on the internet. It is one of the more easily used web-based tools and

8 Journal of Practice Teaching \& Learning 7(3) 2006-07, pp.6-21. DOI: 10.1921/19640. ( $w \& b b$ 
one which has become hugely popular in the last decade (Ballantyne and Quinn, 2006; SIESWE, 2007). It can be public or private; the person setting it up decides who will be able to read entries or 'posts', comment on posts or make new posts. Blogging has been used as a communication tool for several years. The practice has been associated with people on long trips, where they wish to let friends know what they are doing. Many blogs are viewed in an informal context as monologues by people passionate about a particular topic or just keen to 'talk' to whoever might subscribe to or visit their blogs. Blogging has become a political tool in countries where freedom of speech is curtailed and can also be a valuable source of detailed information about the lives of people who are cut off from mainstream global communications (BBC, 2007). Although not usually seen as a two-way communication process (Watson, 2007b), in recent years blogging is being explored as an educational tool and it is in this context that this paper is situated.

There is broad agreement in the literature about the term 'elearning', one definition of which is 'education and training utilizing information technology, such as computers and communication networking' (AEN, 2007). 'Networked learning', defined by Goodyear (2002, p.56) as 'learning in which communications and information technology is used to promote connections: between one learner and other learners; between learners and tutors; between a learning community and its learning resources', may be a more relevant term in discussing the practice application of some web 2.0 tools, including blogging. It is the connection between student and practice teacher which is the key element of any learning tool used on placement.

\section{Context of project}

In the spring of 2007, I worked as an independent Practice Teacher with four individual students, two of whom were based in small voluntary organisations and two of whom were placed in the same large statutory setting. They were all on the same social work programme and were required to maintain a reflective diary of their learning which would be used as a basis for discussion and teaching within our weekly supervision session. When the Practice Teacher and student are co-located the student makes the diary available to the Practice Teacher some time before the

9 Journal of Practice Teaching \& Learning 7(3) 2006-07, pp.6-21. DOI: 10.1921/19640. ๑ wEb 
supervision meeting. With Practice Teachers increasingly working at a distance from the student, it is becoming common for students to email their diary entry to the Practice Teacher. I wanted to take this idea of using technology a step further and knew that blogging was a tool which could enhance the process of sharing journal entries.

This group of four students comprised four women. Two of these were in their early twenties, one knew what blogging was and seen friends' blogs but never read, commented on or written blog entries and one who had read blogs, had set up her own travel blog but had never commented on other people's blogs. The other two students were in their late thirties, neither had ever heard of blogs and one was anxious about ICT in general while the other felt fairly comfortable with email and word processing.

\section{Setting up blogs}

I suggested to each of the students that we should use blogging for reflective journals. I outlined the advantages as:

- I could access the weekly entry as soon as it was posted and the student only had to access the blog and write the entry - the process of sending me the diary was thus simplified for them

- Posting and commenting on blog entries establishes a dialogue which is additional to our weekly supervision meetings and so enhances the support which I would be able to offer

- All entries would be in the same place and easily consulted or searched by the student and by me for our reports/assignments. There is a facility to add labels to each entry to facilitate searching - those labels or tags could be 'ageing', 'confidentiality', 'supervision' and so on.

- The development of the students' web 2.0 skills would help them meet the ICT requirements of the social work degree, which require all qualifying social workers to be competent in the use of such technologies.

The younger students responded positively to this suggestion and each quickly set up a blog for this purpose on their own blog system, inviting me as a 'friend' or 'author' and making the blog private to the student and me only.

10 Journal of Practice Teaching \& Learning 7(3) 2006-07, pp.6-21. DOI: 10.1921/19640. @ w\&b 
Blogging as a reflective journaling tool

\section{Considering and overcoming hurdles}

As I had not used blogging in this way before, I needed to consider a number of potential problems. In the first place I explored the privacy issue; while no identifying details would normally be used in a reflective journal, the security of the blog must be assured so as to protect the student and her clients. Learning technology colleagues were generous in sharing ideas about this and I was reassured that blogs with restricted access were secure. Giving in to a touch of paranoia, I tested this out with friends with some web 2.0 expertise whom I invited, with the students' permission, to try to read the blogs. I was reassured when they were unable to access any posts, all they could do was see the title of the blog but not even the titles of the posts.

The next hurdle was choosing the technology to use. I tried to find a social networking space where I could host a number of blogs and registered with Elgg (www.elgg.org). Elggspaces is a site used by educationalists but as I had not used social networking before I had difficulty understanding how it worked. In a social networking site one normally works within a community where all the blogs are visible to all members of that community. It is possible to have a series of communities and a blog in each community but this would be quite cumbersome and if I did not find it easy, I could not suggest it to students. An ICTcompetent friend tried to help but he, too, found it a challenge so it was clear that this was not a suitable tool to use with less than confident students. I had to find a way to reduce the barriers for all students and make it easy for them to work with a blog.

Meanwhile the younger students had established their blogs on commercial blogging sites used by them or their friends. This worked well except that I had to log into two different host sites in order to read the blogs or to check if there were new posts, as it is not normally possible to use RSS feeds ${ }^{1}$ with private blogs or sites. To be efficient in the use of my time and to ensure that I was able to check the blogs regularly I wished to have them all on one site and so I explored a range of possibilities and concluded that the best available option was Google Blogger (www.blogger.com), where one can set up multiple blogs, each with its own privacy settings.

11 Journal of Practice Teaching \& Learning 7(3) 2006-07, pp.6-21. DOI: 10.1921/19640. (C wEb 
Moira Dunworth and Non Scantlebury

\section{My solutions}

In working up to using email and blogs I supported the students in developing their word-processing skills through minute-taking. It was agreed that we would approve the minutes by email. Writing minutes is a necessary skill in any professional role and I used this situation to help the students to work on this skill by inserting comments and tracking changes to their initial draft. Using 'tracked changes' was a new tool to all of the students and I introduced them to it by requesting their shopping list or to-do list which they sent me as an email attachment. I then made comments and changes to this and returned it to them. This non-threatening and light-hearted introduction enabled them to understand the word-processing tools of tracked changes, attachments and cut-and-paste and then to use them with the minutes, so that they enhanced their word processing and minute taking skills simultaneously. At a later point, when I was happy with how the minutes were being written, one of the more confident students used the blog as a repository of minutes.

To facilitate the less confident students' engagement in blogging, I set up two empty blogs in Google Blogger and invited the non-blogging students each to join one, which they were able to do by just clicking on the invitation. By configuring the 'permissions settings' on Blogger, I restricted the ability to create posts, read posts or comment on posts to the student and myself. Students were not able to read each other's blogs and no-one except me could read what they wrote. In an effort to be friendly and accessible, I posted a photo of myself on each blog and encouraged the students to do the same. By posting my photo onto my Blogger site it appeared on each blog automatically. None of these students posted a photo during this placement, however they were thrilled to have achieved blogging at all. In future I could take their photos and, with their permission of course, could upload these for them, further reducing the barriers. Bearing in mind professional and personal concerns about confidentiality and data protection, I agreed to delete the blog once the exam board had confirmed their results and any need that I might have for the blog content would have passed. If they want to retain the content they could copy it to another location and be solely responsible for it.

For future use, I would recommend establishing a number of blogs on Blogger in advance of the start of the placement and invite each student to one blog in the first week of the placement. Reflecting on my own use

12 Journal of Practice Teaching \& Learning 7(3) 2006-07, pp.6-21. DOI: 10.1921/19640. (C) wEb 
Blogging as a reflective journaling tool

of the technology and on the basis of my increased confidence in using this tool, I will be able to offer more support at the early stages of using the blog and I am optimistic that future groups will be able to engage more actively with the possibilities of the blog by posting photos and links. I would like to supplement this by providing a virtual space for the students where they could share resources and ideas and get mutual support. This could be achieved through a social networking site and would be added value, not a requirement of blogging.

\section{Impact on the students' reflection}

During the placement I discussed with all my students the nature and purpose of reflective writing and the challenges for students of being required to reflect as part of their assessed work. We explored the argument that reflection should not be assessed as there is an inherent tension between the two processes; assessment is about one's best work and reflection is often about uncertainty and anxiety (Boud, 1999). I was keen to allow the students space to engage in private reflection alongside the diary that I would see, on which I would comment and which I use to inform my assessment.

Writing a paper journal makes it difficult to separate out parts of a reflective account, or 'de-rant', where the student has a need to express frustrations. Presenting a journal as a blog affords the opportunity for the student to write it as a separate document and then copy and paste it into the blog, either in its original format or as an edited version. The very process of doing this, and of discussing it in supervision, opened an opportunity to develop the students' understanding of the purpose of reflection as a learning tool.

One student who blogged her reflective journal from the beginning, filtered her reflections in this way and reflected that this enabled her to sort out her thoughts and to separate out the aspects which belonged in the journal which was shared with me. She learnt a considerable amount from her private entries, 'I learnt a lot about myself from what I first wrote down'; the process of writing those helped her to explore her feelings and responses and situate herself as a learner. The advantage of a blog in this respect is that the private reflections are not lost - they are retained in another format. A hand-written journal makes this process more difficult and the student would have to start a separate paper

13 Journal of Practice Teaching \& Learning 7(3) 2006-07, pp.6-21. DOI: 10.1921/19640. (C wEb 
journal for more private comments - not an ideal scenario because excerpts from that private journal would have to be manually copied in order to appear again in the shared journal. One student reported that blogging her reflective journal felt more intimate than writing it in her notebook, 'books can be shut but opening your soul onto a computer can be scary'.

\section{Outcomes}

- Development of ICT skills and confidence for the students. This was particularly marked in the older students who were less confident at the outset. They reported great pleasure in the sense of achievement of overcoming their anxiety and successfully posting to and reading their blogs. These two students had difficulty with word-processing tools at the start of the placement but engaged enthusiastically with blogging in the final weeks and were thrilled to be able to use this tool.

- Like Tolmie and Boyle's (2000) students, my students understood how and why learning this new tool would be helpful for them, the influence of task ownership is visible here: when the group themselves wanted to achieve something using computers, they made it happen.' (p.134).

- One of my older students reported her pleasure in showing off her new skill to her teenage daughter, thus enhancing her confidence in roles other than that of student. - 'she thinks that she is better at computers than me, but I told her about my blogging'.

- Another student reported that she set up a blog for a youth group with which she works, thus feeling more able to "communicate with the young people in a way that they like and understand - I'm cool, really!' All the students expressed pleasure at having developed a new, and transferable, skill.

- A reduction in the time required sharing the reflective journals in another medium. In a situation where the students are under the pressure of competing demands, blogging their diary and minutes reduced that pressure a little.

- The students' reflections could be more considered and could be presented in a more tailored way than is possible with a handwritten journal.

- It was quick and easy for me, the Practice Teacher, to monitor activity

14 Journal of Practice Teaching \& Learning 7(3) 2006-07, pp.6-21. DOI: 10.1921/19640. ๑ wE-b 
on the blog and to respond quickly. I usually commented on a post, even if only to say 'this is very interesting and we must pick it up at supervision'. This increased and enhanced my contact with, and support of, the students between our weekly meetings.

- Blogging enhanced the support that I was able to offer students who were not located with me or each other. This was important in the aftermath of a number of crises for the students, when I was able to affirm support in my comments on their posts about the incidents which had been challenging for them. Reassurance in a written form can sometimes be heard more easily than that provided verbally in the immediate context of the incident.

\section{Reflections on the project}

This was an interesting and worthwhile project that enabled me to develop my skills in blogging so as to use this tool with students. These students are required to be competent in ICT by the time they qualify and the tools available to them are being developed faster than many students can master them. Using blogging as part of the overall ICT expectations in my relationship with students has given them a new tool and new confidence in their ICT abilities and enabled me to improve my communication with, and support of, them at a distance.

In introducing any new web-based tool it is vital to be aware of the students' anxieties and needs and to ensure that there is enough offline support for them to engage with that tool. There will be students who do not wish to engage in this way but, in this project, with an expectation of such engagement and an easy route to the tool, even the reluctant students took on and met the challenge. In working towards these solutions, my expectations of the students in terms of their use of ICT were higher than that to which they had been accustomed. It was interesting that they rose to this challenge; the younger students welcomed the blog as it fitted with their way of communicating and both older students requested the opportunity to try blogging towards the end of the placement.

They were also all pleased to have enhanced their word-processing skills because of the practice involved. The findings from this project suggest that students will engage with blogging when the purpose is 
clearly defined. Blogging was offered as a tool to achieve work already on their schedule. It was not an additional task for them, but rather an alternative way of completing an existing task. The social work students' responses to the suggestion of using blogging as a reflective journal centred on time; the younger students saw it as a time-saving way of completing this required task, while the older students initially thought that it would entail more time.

Looking back on their first reactions the younger students reported being relieved when the idea was first mooted. 'This is easier, it will save me time' and 'I thought that this would mean more time on the computer but then realised that it would be easier - fewer bits of paper and I would only have to write it once'. The older students also focused on time, 'what? Something else to learn?' 'I imagined that it would be difficult and take up time', and on lack of skill, 'oh dear, oh no, I might not be able to do this, I might break the computer'. When asked why they wanted to start blogging later in the placement the older students responded in terms of learning a new skill and of not wanting to be left behind, 'I saw the other student do it and I thought that if she could do it, so could I'. During the post-placement interviews all the students discussed the advantages of blogging in terms of saving time when writing the journal but also saving time when writing essays and reports as it was easy to search the blog for the evidence that they required.

\section{Challenges of reflective writing in social work education: Is it different by blog?}

Reflective writing plays a key role in social work education and can be difficult for the student who has learnt the rules of academic writing but is now required to write in a different way (Rai, 2006). While the student may have encountered differing expectations across disciplines, or even in classes within the same discipline (Lea and Street, 1998; Rai, 2004) the requirement to write reflectively often presents the greatest challenge as they are asked to write about themselves and they may not be confident about which 'self' is required. Lillis (2001, cited in Rai, 2004 and 2006) shares the perspectives of black students who felt that they had to write with a 'white' voice. Blogging can help to address some of these anxieties as the initial writing is only between the student and the practice teacher.

16 Journal of Practice Teaching \& Learning 7(3) 2006-07, pp.6-21. DOI: 10.1921/19640. @ wE-b 
The students in this project valued the immediacy of blogging; they knew that I could read it immediately it was posted and they usually had comments on their entries within a day or two. When interviewed some months later, they did not consider that the content of what they wrote was any different than it would have been in another journal format, but they mostly found it an easier medium, perhaps because it was on the computer screen rather than on paper, with the air of finality that the (paper) written word can evoke. One student reported that her work was more structured when she blogged as she liked to word-process it first, then edit and then post to the blog - she found this to be a quick and helpful way to 'sort out' her thinking. The other students wrote directly onto the blog, or word-processed it and then copied it unedited to the blog. This latter strategy was to avoid computer crashes while writing the blog, which had happened and had resulted in the student losing her unsaved work. Only one student edited work before presenting it in the blog.

These students reported feeling very supported by the blogging process; they appreciated the more immediate feedback that was possible and they felt reassured that I could read it as soon as they had posted it. Their reflections on blogging as a reflective journal are in line with Westbrook (2006) who argues for taking the advantages of online learning without leaving behind the positives inherent in personal interaction in the learning process. Blogging in this context seems to have enhanced the personal interaction rather than reduced it.

\section{Conclusion}

This paper outlined how I used blogging as a reflective journal tool with four students, what issues arose and what outcomes were identifiable. The report of this work is set in the context of elearning and the use of web-based tools in education. Reference is made to reflective writing in social work education and the issues that might arise regardless of the medium used.

The initial response from students seemed to be related to their age, but these differences reduced as the older students engaged in the process and all four students reported that the process helped them to learn or to develop skills in word processing and in engagement with web-based tools. One student directly transferred her learning to work 
with young people and others reported greater confidence in exploring the web and working with computer-based applications.

Whilst this article highlights a particular case study in the application of blogging in a formal educational context, there are a number of broader issues which need further investigation and resolution, especially if we are to encourage mainstreaming and take up of the full potential of these technologies to support good practice developments. The full power of blogging to encourage constructive dialogue, reflection, commentary and resource sharing is aptly demonstrated by an example supplied by Watson (2007b), 'The charity Drugscope uses a daily post to highlight recent research articles in a discursive manner which gives users familiar with the web an accessible means of keeping up to date with the literature, without having to struggle with Boolean searching of an online database' (p.43). This approach challenges much current practice around library and information management support for practitioners.

Along with the studies mentioned, this case study has highlighted the need to consider issues around identity and security management and policy guidelines for blogging in a social work context. There is a growing body of evidence which demonstrates the potential of blogging to excite debate and share and publish knowledge for practitioners. We must endeavour to build on this potential and add value to the existing framework to include other web 2.0 tools such as tagging and rating technologies which further encourage practitioners to link to RSS newsfeeds, filter and link to evolving content, and interlink with communities of interest and practice in a conversational context (Watson, 2007b; Davison Turley, 2005; Ojala, 2005)

\section{Practice pointers}

A number of issues about blogging as a reflective journaling tool may be of concern to practice teachers and I have shared how I dealt with them with a view to facilitating other practice teachers to try this tool.

- Confidentiality can be maintained by setting the privacy options so that only the student and Practice Teacher can read, write or comment on anything in the blog. Others can see the title, but nothing else.

18 Journal of Practice Teaching \& Learning 7(3) 2006-07, pp.6-21. DOI: 10.1921/19640. @ w\&bb 
- The Practice Teacher must be confident in the use of whatever tool is being introduced. The easiest way to do this is to 'play' with that tool socially. My experience is that friends and colleagues were very happy to engage with my experimentation with blogs, as I tried out various providers and settings. Those same friends then, at my request, tried to read the student blogs. When they failed to do so, I was reassured about the privacy settings. In spite of these precautions one would expect not to read any information on the blog which might identify a service user or colleague; the same standards of confidentiality would be applied to this tool as to a paper version of a reflective journal.

- Lisewski and Joyce (2003) point out that teachers have to be comfortable with technological tools if they are to use them effectively with students. With this in mind readers can experiment with a live blog on http://demoptblog.blogspot.com/ where I have created a demonstration reflective journal, using anonymised material from student blogs, with the permission of those students. Readers may wish to take the part of the practice teacher and comment on the students' posts - or even be a student!

\section{Acknowledgements}

The engagement of my students in this project was essential to its success and their permission to write it up has made this paper possible. I appreciate their sharing my sense of adventure. Colleagues on the Open University 'Clusters' project were very helpful in supporting the writing of this paper by commenting on early drafts and asking questions.

\section{Note}

1. RSS is a way of notification of updated content such as blog entries, news headlines or podcasts. It makes it possible for people to keep up with their favorite web sites in an automated manner that's easier than checking them manually.

19 Journal of Practice Teaching \& Learning 7(3) 2006-07, pp.6-21. DOI: 10.1921/19640. (C wEb 


\section{References}

AEN, Asia e-Learning Network (2006) http://www.asia-elearning.net/content/ aboutEL/index.html [accessed 7th November 2006]

Ballantyne, N and Quinn, K. (2006) Informal Learning \& the Social Web. available from http://informallearning.pbwiki.com/

BBC (2007) http://news.bbc.co.uk/1/hi/sci/tech/2044802.stm

Boud, D. (1999) Avoiding the traps: Seeking good practice in the use of self assessment and reflection in professional courses. Social Work Education, $18,2,121-132$

Cha, T., Kuo, E., and Marsh, J.C. (2006) Useful knowledge for social work practice. Social Work and Society, 4, 1. Available from http://www.socwork. net/2006/1/debate/chakuomarch

Davison Turley, W. (2005) Blogs and RSS: Powerful information management tools. Library Hi Tech News, 22, 10, 28-29

Dearstyne, B.W. (2005) BLOGS The new information revolution? Information Management Journal, 39, 5, 38-44

Forrest, J. and Williams, S. (1987) New Technology and Information Exchange in Social Services. London: Policy Studies Institute

Goodyear, P. (2002) Psychological foundations for networked learning. in C. Steeples, C. and C. Jones (Eds.) Networked Learning: Perspectives and Issues. Berlin: Springer Verlag, 49-75. available from http://www.amazon. co.uk/Networked-Learning-Perspectives-J-Michael-Spector/dp/1852334711/ ref=sr_1_2?ie=UTF8 \&s=books\&qid $=1195763460 \& s r=8-2$

Lea, M and Street, B. (1998) Student writing in higher education: An academic literacies approach. Studies in Higher Education, 23, 2, 157-172

Lillis, T. (2001). Student Writing Access, regulation and desire. London: Routledge

Lisewski, B. and Joyce, P. (2003) Examining the five-stage e-moderating model: Designed and emergent practice in the learning technology profession. ALT-J, 11, 1, 55-66

Ojala, M. (2005) Blogging for knowledge sharing, management and dissemination. Business Information Review, 22, 4, 269-276

Rai, L (2004) Exploring literacy in social work education: a social practices approach to student writing. Social Work Education, 23, 2, 149 - 162

Rai, L. (2006) Owning (up to) reflective writing in social work education. Social Work Education, 25, 8, 785-797

Sharpe, R., Belfield, G., Roberts, G. and Francis, R. (2006) The undergraduate

20 Journal of Practice Teaching \& Learning 7(3) 2006-07, pp.6-21. DOI: 10.1921/19640. (C) wEb 
experience of blended e-learning: A review of UK literature and practice. The Higher Education Academy, available from http://www.heacademy.ac.uk/ ourwork/research/litreviews/2005_06

The Scottish Government (2003) The Framework for Social Work education in Scotland. available from http://www.scotland.gov.uk/Publications/2003/01/16 202/17018

Scottish Institute for Excellence in Social work Education (2007) Blogging, SIESWE Learning Technology Infosheet \#4. available from http://www.sieswe. org/node/228

Tolmie, A. and Boyle, J. (2000) Factors influencing the success of computer mediated communication (CMC) environments in university teaching: A review and a case study. Computers \& Education, 34, 2, 120-140

Watson, M. (2007a) Knowledge management in health and social care. Journal of Integrated Care, 15, 1, 27-33

Watson, M. (2007b) Knowledge management and staff expertise in health and social care. Journal of Integrated Care, 15, 5, 41-44

Westbrook, V. (2006) The virtual learning future. Teaching in Higher Education, $11,4,471-482$ 